\title{
Unintended Pregnancy and Abortion Access in the United States
}

\author{
Marshall H. Medoff \\ Department of Economics, California State University, Long Beach, 1250 Bellflower Boulvard, Long Beach, CA 90840, USA \\ Correspondence should be addressed to Marshall H. Medoff, marshall.medoff@csulb.edu
}

Received 26 March 2012; Revised 27 May 2012; Accepted 10 July 2012

Academic Editor: Bridget Freisthler

Copyright (C) 2012 Marshall H. Medoff. This is an open access article distributed under the Creative Commons Attribution License, which permits unrestricted use, distribution, and reproduction in any medium, provided the original work is properly cited.

\begin{abstract}
This study examines the relationship between state restrictive abortion laws and the incidence of unintended pregnancy. Using 2006 data about pregnancy intentions, the empirical results found that no Medicaid funding, mandatory counseling laws, twovisit laws, and antiabortion attitudes have no significant effect on the unintended pregnancy rate, unwanted pregnancy rate, unintended pregnancy ratio, or the unwanted pregnancy ratio. Parental involvement laws have a significantly negative effect on the unintended and unwanted pregnancy rates and ratios. This latter result suggests that parental involvement laws alter teen minors' risky sexual activity and that behavioral modification has a cumulative effect on the pregnancy avoidance behavior of adult women of childbearing age. The empirical results remain robust even after controlling for regional effects, outliers, and the two different types of parental involvement laws.
\end{abstract}

\section{Introduction}

One in twenty American women had an unintended pregnancy in 2001 [1]. In 2001, almost half of the 6.4 million pregnancies were unintended and about half of these ended in abortion [1]. The costs to society from unintended pregnancies that end in unintended births have received considerable attention from social scientists. Sonfield et al. [2] estimated that the government costs on births from unintended pregnancies totaled $\$ 11.1$ billion in $2006-\$ 6.5$ billion were federal expenditures and $\$ 4.6$ billion were state expenditures. Or equivalently, the federal government and state governments spent, in total, $\$ 180$ on maternity and infant care on births from unintended pregnancies for every women of childbearing age 15-44 years in the United States in 2006. Unintended births also have numerous undesirable consequences including low birth weight, a greater risk of physical abuse and mental illness, and high rates of poverty, unemployment, and educational failure.

There is a broad consensus among policymakers that reducing the incidence of unintended pregnancies is an important public and social policy goal. In fact, three of the explicit policy goals of the US Department of Health and Human Services Healthy People 2020 initiative was to (1) reduce the number of unintended births, without increasing the number of abortions; (2) increase the proportion of pregnancies that are intended; (3) increase the proportion of females at risk of an unintended pregnancy who used contraception at their most recent sexual intercourse.

Of particular interest to social scientists are public policies that affect the costs to women of risky sexual activity (i.e., the frequency of noncontracepted sexual activity) that leads to unintended pregnancies. One public policy that affects the costs of risky sexual activity is state restrictive abortion laws. The likelihood of an unintended pregnancy represents a cost of risky sexual activity. As access to an abortion becomes more difficult (costly), because of restrictive abortion laws, the expected cost of an unintended pregnancy increases since abortion is an ex postbirth control method or insurance against an unintended pregnancy, implying that there should be a reduction in the propensity of women to engage in risky sexual activity. Restrictions on abortion access increase the cost of noncontracepted sexual activity and should therefore decrease risky sexual activity.

A substantial literature has found that, in general, state restrictive abortion laws reduce the incidence of abortion [37]. However, whether there is an association between state restrictive abortion laws and the incidence of unintended pregnancy is largely an unexplored important issue. One reason has been the unavailability of unintended pregnancy 
data. The Centers for Disease Control's Pregnancy Risk Assessment Monitoring System (PRAMS) conduct a statespecific survey of women's pregnancy intentions before, during, and after a birth. Using the PRAMS' intention data plus similar state survey data, Finer and Kost [8] calculated state-level estimates of the proportion of births that were unintended and applied these proportions to the total number of births reported for each state for 2006 from the US Vital Statistics Report. This data combined with the number of abortions obtained by residents of each state (and fetal losses) was used to estimate the unintended pregnancy rate for all 50 states in 2006. Finer and Kost's data makes it possible to examine whether there is an association between state restrictive abortion laws and the incidence of unintended pregnancy.

The purpose of this paper is to use this 2006 data source to empirically examine the question of whether state regulations restricting abortion access are associated with lower unintended pregnancy rates. The question of whether restrictive abortion laws have an effect on the incidence of unintended pregnancies has significant public and social policy implications. Given the social costs related to birth from unintended pregnancies, evidence of an association between restrictive abortion laws and unintended pregnancy has profound implications for public policy.

\section{Restrictive Abortion Laws}

Since the US Supreme Court's 1973 Roe v. Wade decision legalizing abortion, states have enacted a variety of laws regulating the access and availability of abortion services. There are four types of restrictive abortion laws enacted by states that the Supreme Court has held to be constitutional (an overview of the history of US Supreme Court's rulings on state restrictive abortion laws is provided by Lewis and Shimabukuro [9]).

Medicaid is a joint federal-state program that provides health insurance to the poor. It is administered at the state level, but its financing is equally split between the federal and state governments. In 1980, the Supreme Court in Harris v. McRae ruled that prior congressional legislation (i.e., the Hyde Amendment) prohibiting the use of federal funds to reimburse states for the cost of an abortion performed on a woman on Medicaid was constitutional. After this ruling, many states enacted laws that prohibited the use of their public funds to pay for Medicaid abortions. In these states, poor women on Medicaid have to pay the entire out-ofpocket cost of an abortion.

In the years following the Roe v. Wade decision, the Supreme Court, in the cases of Planned Parenthood Central Missouri v. Danforth and Bellotti v. Baird, held that pregnant teen minors (less than 18 years of age) are constitutionally entitled to make the decision to have an abortion without unreasonable state interference. But the Supreme Court also held a state's interest in protecting the health and safety of a teen minor to be sufficient to require parental involvementeither parental notification or parental consent-in a teen minor's decision to have an abortion.
All states require that healthcare providers, prior to performing a nonemergency medical procedure, provide germane information to and obtain consent from patients about the medical procedure. However, in addition to the general informed consent requirements, many states also enacted additional mandatory counseling laws that apply only to abortion. These abortion-specific counseling laws require that an abortion provider, usually 24 hours before the procedure, furnishes to every woman state-approved abortion-specific medical information designed to discourage women from obtaining an abortion. Such information may include fetal development (e.g., age, size, pain, potential viability), potential future health risks (e.g., suicide, breast cancer, depression), and available public financial assistance.

In most mandatory counseling states, the abortion provider does not have to impart the state-approved medical information in person. The information may be given or offered either written or orally, by telephone, mail, fax, or over the Internet. However, five states have two-visit laws that require women receive their mandatory counseling information in person at least 24 hours before the abortion procedure. Two-visit mandatory counseling states necessitate that women must make two separate trips to the abortion provider which imposes substantial travel expenses and time costs on women seeking an abortion.

In 2006, (i) 33 states did not allow their public funds to be used to pay for an abortion for an indigent woman; (ii) 32 states required some parental involvement in a teen minor's decision to have an abortion; (iii) 24 states mandated that abortion providers give or offer to women state-approved specific-detailed information about the procedure and fetal development; (iv) 5 states required two trips to the healthcare provider, since the mandatory counseling must be given in person at least 24 hours before the abortion procedure. The total number of restrictive abortion laws a state could enforce ranges from zero to four. The average number of state restrictive abortion laws was $1.88($ S.D. $=1.32)$. Five states (Indiana, Louisiana, Mississippi, Utah, and Wisconsin) had all four restrictive abortion laws, and ten states (California, Hawaii, Illinois, Montana, New Jersey, New Mexico, New York, Oregon, Vermont, and Washington) did not have any of the four restrictive abortion laws.

\section{Theory}

Kane and Staiger [10], in a seminal paper, argue that abortion is an ex postbirth control method that provides sexually active women (at risk of a pregnancy) insurance in the event of an unintended pregnancy. The option to have an abortion of an unintended pregnancy lowers the cost to women of engaging in risky (noncontracepted) sexual activity. As the cost of an abortion increases, due to the enforcement of restrictive abortion laws, the cost of this unintended pregnancy insurance policy increases, which may induce women to alter their risky sexual behavior in ways that reduce the likelihood of an unintended pregnancy. In response to these restrictive abortion laws, women may change their frequency of unprotected sexual activity and/or contraceptive use in order to avoid an unintended pregnancy. The Kane and 
Staiger model argues that restrictive abortion laws affect the antecedents of unintended pregnancies - the level of unprotected sexual activity and/or the frequency of contraceptive use-resulting in fewer unintended pregnancies. The Kane and Staiger model implies the hypothesis to be tested in this paper that, ceteris paribus, women residing in states with more abortion restrictions should have less unintended pregnancies than women in states with fewer restrictive abortion laws.

Kane and Staiger's economic model of risky sexual activity is based on rational choice theory. Rational choice theory is a framework for understanding and modeling social behavior. Kane and Staiger's model is predicated on the assumption that women make rational decisions about sexual activity, contraceptive usage, and pregnancy resolution based on a comparison of the respective costs and benefits of each alternative. One of the costs of risky sexual activity is an unintended pregnancy. Women choose the optimal alternative depending on their values and the information they have available to them (i.e., make an economically rational decision). The underlying premise of rational choice theory is that women make choices that are rewarding to them and avoid those that are not. In other words, rational choice theory expects women of childbearing age to respond to incentives. This framework has been applied to the risky sexual activity of childbearing women and the empirical results are generally supportive of the rational choice theoretical approach (a complete review is available in $[3,5,11-$ 13]).

Kelly and Grant [14] and England and Kilbourne [15] argue that the economic model of risky sexual activity does not do justice to the complexity of the decision-making process women consider when engaging in sexual activity. Nevertheless, the economic model of risky sexual activity provides a useful and parsimonious means to theoretically link restrictive abortion laws and risky sexual activity. A focus on economic cost (restrictive abortion laws) does not imply that social, cultural, attitudinal, family, or community factors do not influence a woman's risky sexual activity. Rather, this approach suggests that restrictive abortion laws may have an independent effect on women's risky sexual activity. In particular, an economic rational choice model of women's risky sexual activity suggests that restrictive abortion laws may affect the decisions women make regarding risky sexual activity and contraception in a predictable manner.

\section{Literature Review}

There has been empirical research that has examined the effect of Medicaid funding restrictions and parental involvement laws on teen risky sexual activity.

Levine [16], using the Youth Risk Behavior Survey (which has very few measures of individual socioeconomic characteristics), found that over the period 1991-1997 neither Medicaid funding restrictions or parental involvement laws had an impact on the probability of teen sexual activity or contraceptive use. Similarly, Averett et al. [17], using the 1988 and 1995 National Surveys of Family Growth, found that neither Medicaid funding restrictions nor parental involvement laws affect the probability of a teen being sexually active, and if sexually active, the probability of using contraception.

Levine [18], using the 1988 and 1995 National Surveys of Family Growth, found weak evidence that parental involvement laws reduce teens' unprotected sexual activity largely due to a greater use of contraception, rather than a reduction in teen sexual activity. Sen [19], using data from the 1997 National Longitudinal Survey of Youth, found that neither Medicaid funding restrictions nor parental involvement laws had significant effects on either the frequency of sexual activity nor the frequency of contracepted sexual activity of teens.

In sum, the above studies find no evidence that Medicaid funding restrictions or parental involvement laws have any effect on teens' risky sexual activity. However, all these studies use individual-level survey data on self-reported teen sexual activity, which have several problems. First, self-reported data may have considerable measurement errors due to untruthful or unreliable answers to personal questions about a teen's intimate sexual activity. Second, these surveys only ask teens if they had sexual activity in the prior three months and whether they used contraception during their last sexual encounter and ignored the frequency and regularity of sexual activity and contraceptive use.

Several studies have examined the impact of restrictive abortion laws on risky sexual activity indirectly. Joyce et al. [20] assessed the impact of a parental involvement law that took effect in Texas on January 1, 2000 and required notification of the parents of a teen minor. Comparison of abortion rates two years before and two years after the law took effect showed that the abortion rates for teens ages 15 , 16, and 17 fell. They also did not find any evidence of an increase in births for the respective teen ages. In fact, they found a decrease in teen birth rates. The only way these two findings can be reconciled is if teen pregnancy rates fell (i.e., unprotected teen sexual activity decreased) in response to the enactment of the parental involvement law.

Other studies have examined the impact of restrictive abortion laws and risky sexually activity using cross-section time-series data to examine whether a state Medicaid funding restriction or a parental involvement law affects teen birth/ pregnancy rates. Levine [18], over the period 1985-1996, found that parental involvement laws have a negative impact on teen birth rates in some model specifications and a positive impact in other model specifications. Medoff [21], over the period 1982-2000, found that a Medicaid funding restriction and mandatory counseling reduce teen (ages 1519) and minor teen (ages 15-17) pregnancy rates.

Some studies have examined whether parental involvement laws affect teen risky sexual behavior as measured by teen gonorrhea rates. Klick and Stratmann [22] found that parental involvement laws were associated with a decline in the gonorrhea rates of white teens and Hispanic teen females. They argue that parental involvement laws, by raising the cost of an abortion, induce teens to avoid risky sexual activity. Similarly, Sen [23] finds that reducing abortion access leads to a reduction in female sexually transmitted 
diseases. Sen's estimates are economically significant, but marginally statistically significant.

\section{Empirical Model}

This study analyzes the effect of restrictive abortion laws on the incidence of unintended pregnancy by state for the year 2006. The theoretical model of fertility control argues that the determinants of fertility control are opportunities foregone (e.g., education, labor market experience, marital prospects), and revealed tastes for children and laws restricting abortion access $[24,25]$. The relationship between these variables and the incidence of unintended pregnancy is given by (1). A multivariate regression model of the incidence of unintended pregnancy is estimated in order to control for state differences in the population characteristics of women of childbearing ages ( 15 to 44 years):

Unintended Pregnancy Rate ${ }_{i}=b_{0}+b_{1} R_{i}+b_{2} X_{i}+b_{3}$ State $_{i}$.

The dependent variable is the unintended pregnancy rate-the number of unintended pregnancies per 1000 women of childbearing ages 15-44 years residing in state $i$ for the year 2006. There are 50 state observations (Washington, $D C$, is excluded).

In (1), $R$ is a vector of indicator variables of restrictive state abortion laws: (i) no Medicaid funding equals one if state $i$ prohibited the use of its Medicaid funds to pay for an abortion for poor women in 2006; (ii) parental involvement law equals one if state $i$ had a parental involvement law in effect in 2006; (iii) mandatory counseling law equals one if state $i$ requires abortion providers give to women stateapproved abortion-specific medical information about the procedure in 2006; (iv) two-visit law equals one if state $i$ required its mandatory counseling be done in person at least 24 hours before the abortion procedure, thereby necessitating two separate trips to the abortion provider in 2006. All the restrictive abortion laws were enacted prior to 2003. Data on state abortion laws comes from the Guttmacher Institute [26].

Another abortion cost is women's attitudes or beliefs about abortion that may influence their risky sexual behavior. There may exist differences in women's antiabortion attitudes that are specific to each state. The failure to control for women's antiabortion attitudes may result in spurious estimates of the effects of state restrictive abortion laws on the incidence of unintended pregnancy. NARAL Prochoice America [27] compiled a numerical state ranking from 1 (least restrictive) to 50 (most restrictive) based on the number of policies a state has that restrict women's access to reproductive healthcare in 2005. The greater the value of the NARAL Prochoice America antiabortion attitudes measures, the more a state's women are opposed to abortion.

The control variable $X$ in (1) is a vector of the mean socioeconomic characteristics of women of childbearing age in state $i$ that the literature has found to be associated with women's risky sexual behavior $[3,5,12]$. These include (i) Labor Force Participation-the labor force participation rate of women ages 16-44: women in the labor force have a higher opportunity cost of childrearing; (ii) Collegethe percentage of women ages 25 to 44 who have a college degree: women with greater human capital may have better knowledge about effective contraceptive methods; (iii) Single-the percentage of women ages 16-44 who are unmarried (i.e., single, widowed, separated, and divorced): unmarried women are more likely to have unplanned pregnancies than married women; (iv) Evangelical Christiansthe percentage of a state's population that belongs to a religious denomination that believes that the Bible proscribes premarital sexual activity, contraceptive use, and abortion and encourages large families; (v) Catholic-the percentage of a state's population that is Catholic: the Catholic Church has strong moral prohibitions against the use of artificial contraceptive methods and abortion.

The variable state is a vector of state characteristics including the percentage of the state's population in Poverty and the average Temporary Assistance to Needy Families (TANF) stipend received by an unwed mother with one child in state $i$ in 2006: the amount of a state's public assistance lowers the cost to unmarried women engaging in risky (noncontracepted) sexual activity.

Women may circumvent a restrictive abortion law in their state by obtaining an abortion from an out-of-state provider without such a law. Interstate travel by women across state lines to obtain an abortion is controlled for by including two separate variables suggested by Blank et al. [28] and Haas-Wilson [29]: (1) the number of states bordering state $i$ that did not have a parental involvement law in 2006 and (2) the number of states bordering state $i$ that did not have a mandatory counseling law in 2006.

All the economic data are available in the US Bureau of the Census [30], US Census of the Population, State Reports. There is no bias in using economic data from 2001-2002 rather than 2006 economic data since the economic variables are state averages that change relatively slowly over a fouryear period [31, page 244]. Summary statistics for all the variables are shown in Table 1.

One obvious concern in estimating (1) is the problem of making inferences about individual behavior based on aggregate data for a group (i.e., the ecological fallacy). The central actor in the behavioral link between restrictive abortion laws and risky sexual behavior is an individual, but the unit of observation in the estimation of (1) is all adult women of childbearing age. However, individual-level data on unintended pregnancy suffers from the problem that abortions are highly underreported in surveys of women [32]. As noted by Kost et al. [33, page 57], because of the limitations in survey data, "... an aggregate-level study is the only feasible approach to studying variation in unintended pregnancy rates." Since the focus of this study is whether restrictive abortion laws induce a modification in the decision-making calculus sexually active women of childbearing age make regarding unprotected sexual activity and contraceptive use, the aggregated effects of these decisions will be evident in the unintended pregnancy rates of all women of childbearing age. 
TABLe 1: Summary statistics.

\begin{tabular}{lcc}
\hline Variable & Mean & $\begin{array}{c}\text { Standard } \\
\text { deviation }\end{array}$ \\
\hline Unintended pregnancy rate (women ages 15-44) & 51.8 & 9.05 \\
Labor force participation (women ages 16-44) & 83.8 & 2.85 \\
Percent of Single (women ages 16-44) & 35.4 & 4.13 \\
Percent of College (women ages 25-44) & 22.4 & 4.06 \\
Percent of Evangelical Christians & 14.5 & 13.5 \\
(state population) & 19.6 & 12.4 \\
Percent of Catholic (state population) & 336.4 & 135.9 \\
TANF (average stipend) & 8.7 & 2.76 \\
Percent of Poverty (state population) & .66 & .47 \\
No Medicaid funding (=1) & .64 & .48 \\
Parental involvement laws (=1) & .48 & .50 \\
Mandatory counseling laws (=1) & .10 & .30 \\
Two-visit laws (=1) & 25.50 & 14.56 \\
Antiabortion attitudes & & \\
\hline
\end{tabular}

\section{Empirical Results}

Equation (1) was first estimated using ordinary least squares. A plot of the residuals showed that the error variances decreased as the number of females of childbearing ages (1544 years) increased. In order to achieve efficient estimates, (1) was reestimated using generalized least squares; specifically, each observation was weighted by the square root of the number of females of childbearing ages (15-44 years) in each state [31].

The generalized least squares regression results of (1) when the dependent variable is the unintended pregnancy rate of childbearing age are shown in Table 2 , column 1 . Because of space limitations, only the regression coefficients for the abortion cost variables from (1) are reported (the complete empirical results are available in Table 3). Each entry in Table 2 represents the regression coefficient of the four types of restrictive abortion laws or the antiabortion attitudes variable (as well as the absolute value of the $t$ statistic in parentheses below the regression coefficient).

The empirical results reported in Table 2, column 1, that indicate no medicaid funding, mandatory counseling laws, two-visit laws, and antiabortion attitudes have no significant impact on the unintended pregnancy rate of women of childbearing age. Medicaid funding restrictions, mandatory counseling laws, two-visit laws, and antiabortion attitudes do not significantly alter women's pregnancy avoidance behavior. Parental involvement laws, however, have a significant negative effect on the unintended pregnancy rate of women of childbearing age $(P<0.001)$. This finding may seem paradoxical since parental involvement laws only impact the pregnancies of teen minors (less than 18 years of age) which represent less than 6 percent of all pregnancies. Nevertheless, this finding is entirely consistent with the hypothesis that the enforcement of parental involvement laws, by making unprotected sexual activity more costly, may have temporal effects that induce a permanent change in the risky sexual behavior of teen minors which is perpetuated as they age.
The presence of this behavioral modification effect is supported by Joyce and Kaestner's [34] finding that in Mississippi and South Carolina, after the enactment of a parental involvement law, the abortion rates of nonminor teens who were not affected by the law fell and Tomal's [35] finding that the enforcement of a parental involvement law decreased the birth rates of both minor and nonminor teens. In addition, Jones et al. [36], using 2003-2004 survey data, found that if parental involvement were required, 91 percent of teen minors whose parents did not know they were patients at a family planning clinic would use over-thecounter contraceptives, obtain birth control prescriptions from private doctors, or stop having sex, while only 9 percent would continue to have sex, but use no birth control method. These results suggest that parental involvement laws may cause changes in the pregnancy avoidance behavior of teen minors that persist over adult fertile women's entire childbearing span of 18-44 years of age.

The previous estimate of (1) examined the unintended pregnancy rate. However, the unintended pregnancy rate may have declined not because of the enforcement of a parental involvement law, but because of a general decrease in pregnancy rates due to the diffusion of more efficacious birth control methods, a heightened awareness of the healthcare risks associated with unprotected sexual activity, more conservative attitudes about sexual activity, or welfare reform policies that provided less financial assistance to unwed mothers [37].

Thus, it is of interest to use as the dependent variable in (1) the unintended pregnancy ratio- the number of unintended pregnancies to the total number of pregnancies-in order to test, for a given number of pregnancies, whether the abortion cost variables reduce the incidence of unintended pregnancy. The empirical results appear in Table 2, column 2.

The empirical results show that, for a given number of pregnancies, no Medicaid funding, mandatory counseling laws, two-visit laws, and antiabortion attitudes do not have a significant effect on the incidence of unintended pregnancies. Parental involvement laws have a significant negative effect $(P<0.001)$ on the incidence of unintended pregnancies, implying that parental involvement laws do alter teen minors' risky sexual behavior and that change has a cumulative effect on the pregnancy avoidance behavior of adult women of childbearing age.

The Centers for Disease Control defines a pregnancy as unintended if it was mistimed (a woman wanted to become pregnant, but at a later date) or unwanted (a woman did not want to become pregnant at any time). The problem with the CDC's definition of an unintended pregnancy is that a pregnancy may be mistimed (unexpected or unplanned), but not necessarily unwanted. Mistimed pregnancies include these that are too soon or much too soon, but not unwanted.

The Finer and Kost data disaggregates unintended pregnancies into those that are mistimed and those that are unwanted for 42 states. The previously reported empirical results may be spurious because in nearly every state between 65 and 75 percent of unintended pregnancies are described as mistimed. The insignificant effects of the abortion cost 
TABLE 2: Regression coefficients of abortion cost variables.

\begin{tabular}{|c|c|c|c|c|}
\hline \multirow[b]{2}{*}{ Abortion cost variables } & \multicolumn{4}{|c|}{ Dependent Variable } \\
\hline & $\begin{array}{c}\text { Unintended } \\
\text { pregnancy rate (1) }\end{array}$ & $\begin{array}{l}\text { Unintended pregnancy } \\
\text { ratio }(2)\end{array}$ & $\begin{array}{l}\text { Unwanted pregnancy rate } \\
(3)\end{array}$ & $\begin{array}{c}\text { Unwanted pregnancy ratio } \\
(4)\end{array}$ \\
\hline No Medicaid funding & $.0385(.63)$ & $.0478(1.27)$ & $.0888(1.11)$ & $.0281(.47)$ \\
\hline Parental involvement laws & $-.1697(3.07)^{* *}$ & $-.1059(3.13)^{* *}$ & $-.1698(2.39)^{*}$ & $-.0820(2.52)^{*}$ \\
\hline Mandatory counseling laws & $-.0256(.49)$ & $-.0165(.51)$ & $.0161(.23)$ & $.0791(1.45)$ \\
\hline Two-visit laws & $-.0741(1.13)$ & $-.0613(1.53)$ & $-.0841(.99)$ & $-.0344(.54)$ \\
\hline Antiabortion attitudes & $.0031(1.46)$ & $.0033(1.55)$ & $-.0001(1.06)$ & $.0011(.50)$ \\
\hline$R^{2}$ & .79 & .76 & .69 & .67 \\
\hline
\end{tabular}

Note: Absolute value of $t$-statistics in parentheses $\left({ }^{* *} P<0.01,{ }^{*} P<0.05\right)$. Each column represents the coefficient from a generalized least squares regression model and the other independent variables are Labor Force Participation, percent of Single, percent of College, percent of Evangelical Christian, percent of Catholic, TANF, percent of Poverty, NARAL and border state parental involvement and mandatory counseling laws as described in the text.

TABLE 3: Regression coefficients of independent variables (absolute value of $t$-statistics in parentheses).

\begin{tabular}{lcccc}
\hline \multirow{2}{*}{$\begin{array}{l}\text { Independent variables } \\
\text { NARAL }\end{array}$} & Unintended pregnancy rate & Unintended pregnancy ratio & Unwanted pregnancy rate & Unwanted pregnancy ratio \\
\hline $\begin{array}{l}\text { Labor force } \\
\text { participation }\end{array}$ & $.0031(1.46)$ & $.0033(2.55)^{* *}$ & $-.0001(.06)$ & $.0010(.50)$ \\
Percent of College & $.0338(10.1)^{* *}$ & $.0388(16.6)^{* *}$ & $.0211(4.27)^{* *}$ & $.0337(9.07)^{* *}$ \\
Percent of Single & $.0120(1.32)$ & $.0018(.32)$ & $.0167(1.42)$ & $.0051(.57)$ \\
Percent of Evangelical & $.0052(.70)$ & $.0103(2.25)^{*}$ & $.0178(1.83)$ & $.0111(1.55)$ \\
Christians & $.0003(.15)$ & $-.0031(2.02)^{*}$ & $-.0018(.55)$ & $-.0032(1.31)$ \\
Percent of Catholic & $-.0032(1.16)$ & $-.0047(2.76)^{* *}$ & $-.0041(1.13)$ & $-.0026(.98)$ \\
Percent of Poverty & $.0590(6.82)^{* *}$ & $.0519(9.78)^{* *}$ & $.0489(4.36)^{* *}$ & $.0290(3.94)^{* *}$ \\
TANF & $.0010(.55)$ & $.0001(.65)$ & $-.0001(.13)$ & $.0001(.02)$ \\
\hline
\end{tabular}

${ }^{* *} P<0.01 ; * P<0.05$.

variables (except for parental involvement laws) reported previously may have been confounded by the aggregation of the two types of unintended pregnancies into one variable. Restrictive abortion laws may only affect the risky sexual activity of women who did not want to become pregnant now or at a later date.

In order to take into account this possibility, (1) is reestimated with the dependent variable being the unwanted pregnancy rate-the number of unwanted pregnancies per 1000 women of childbearing ages 15-44 in state $i$ during 2006. The empirical results appear in Table 2, column 3. The empirical results show that no Medicaid funding, mandatory counseling laws, two-visit laws and antiabortion attitudes have no significant effect on the unwanted pregnancy rate. Parental involvement laws are significantly negative $(P<0.05)$; which provides further empirical evidence that there is an association between the enactment of parental involvement laws by states and the pregnancy avoidance behavior of adult women of childbearing age previously affected by these laws.

Column 4 of Table 2 shows the empirical results for the abortion cost variables when the dependent variable in (1) is the unwanted pregnancy ratio-the number of unwanted pregnancies to the total number of pregnancies. For a given number of pregnancies, the enforcement of a parental involvement law by a state is associated with a significant reduction $(P<0.05)$ in the number of unwanted pregnancies.

\section{Alternative Specifications}

The previous section provides empirical support for the hypothesis that parental involvement laws induce changes in teen minors' unprotected sexual activity (i.e., the frequency of unprotected sexual activity and/or contraceptive use) which is perpetuated over time, resulting in a reduction in the incidence of unintended pregnancy. One way to test the sensitivity of the previously reported empirical results is to examine alternative specifications of (1).

One of the most frequently mentioned problems in studies examining the relationship between abortion cost variables and women's risky sexual activity is the possibility of omitted variable bias. The econometric technique most often used to control for omitted or unobserved variables is to use a state-specific fixed-effects model (a dummy variable for each state). However, using a state-specific fixed-effects specification to estimate (1) is not possible because the model would be underidentified since there would be more independent variables than the 50 observations for the year 2006. 
A second-best solution is to use a regional fixedeffects specification-including in the estimation of (1) a regional dummy variable for each state from the US Census' classification of the 50 US states into 4 regions (east, midwest, south and west). For all four dependent variables in Table 2, parental involvement laws remain significantly negative and all the other abortion cost variables are still insignificant (complete empirical results available upon request).

In order to test for the presence of outliers, (1) was reestimated for all the dependent variables in Table 2 when the two states with the highest (Mississippi and California) and the two states with the lowest (New Hampshire and Maine) incidence of unintended pregnancy are dropped from the data set. The significant negative effect of parental involvement laws was not substantially affected by the removal of outliers.

There are two types of parental involvement laws. Parental notification laws require that a parent be notified of a teen minor's intent to have an abortion, but the parent may not prevent the minor from obtaining an abortion. Parental consent laws require permission of a parent before the abortion can be performed. Parental consent laws give a parent the legal right to deny their teen minor from having an abortion. Parental consent laws are, in theory, more restrictive than parental notification laws. This suggests that there may be empirical differences between the two types of parental involvement laws, with parental consent laws having a stronger impact on teen minors' risky sexual activity.

In order to test if there are empirical differences between the two types of parental involvement laws, the parental involvement law variable was disaggregated into two separate dummy variables: parental consent law $(=1)$ if a state had a parental consent law in effect and parental notification law $(=1)$ if a state had a parental notification law in effect in 2006. The empirical results show that Parental Consent Law and Parental Notification Law were both significantly negative for all four of the dependent variables in Table 2, but the null hypothesis of equality of coefficients between the Parental Consent Law and the Parental Notification Law variables cannot be rejected. There are no statistically significant differences between the effect of the two types of parental involvement laws on various measures of the incidence of unintended pregnancy and the other abortion cost variables remained statistically insignificant.

In order to determine if the total number of restrictive abortion laws a state enforces has an aggregate predictive effect on the incidence of unintended pregnancy, (1) was reestimated for all the dependent variables in Table 2 with the variable total (no Medicaid funding + parental involvement laws + mandatory counseling + two-visit laws) replacing all four of the indicator restrictive abortion law variables. The empirical results showed that for all four dependent variables that appear in Table 2, the aggregate state restrictive abortion law variable Total was not significantly different from zero. The total number of restrictive abortion laws a state enforces does not have a significant effect on the incidence of unintended pregnancy.

\section{Study Limitations}

The empirical results reported in this paper are subject to several caveats. Despite the inclusion of a number of independent variables that the literature has found to be associated with women's pregnancy avoidance behavior, it is possible that some other factor, that affects women's risky sexual activity, is correlated with a state's abortion policies and antiabortion attitudes. If this other factor was not controlled for, then the impact of this other factor will be incorrectly attributed to a state's restrictive abortion laws or antiabortion attitudes. Cross-section data are especially susceptible to this source of bias.

Another potential problem is that a state's restrictive abortion laws may not be exogenous, but a reaction by state legislators to the level of risky sexual activity in their state. If the enactment of restrictive abortion laws is endogenous, then the estimated coefficients of the restrictive abortion laws and antiabortion attitudes will be biased.

A third concern is that the Kane and Staiger model implicitly assumes that women responding rationally to changes in abortion costs have good information about alternative contraceptive methods and the cognitive ability to weigh the possible ramifications of their risky sexual behavior. This rational choice decision-theoretic modeling approach focuses on economic costs and does not reflect every factor that influences women's decisions about their risky sexual behavior.

\section{Conclusion}

Unintended pregnancies are a major health and social problem in the United States. There is a broad consensus by policymakers that reducing the incidence of unintended pregnancy is an important public and social policy goal. One of the explicit aims of the US Department of Health and Human Services Healthy People 2020 initiative was to reduce the number of unintended births without increasing the number of abortions.

Since the US Supreme Court's 1973 decision legalizing abortion, many states have enacted restrictive laws that reduce the access and availability of abortion. Restrictive abortion laws increase the cost of obtaining an abortion and hence the cost of engaging in noncontracepted sexual activity when an unintended pregnancy is not desired and may decrease risky sexual activity which leads to unintended pregnancies.

This study uses Finer and Kost's state data on pregnancy intentions to empirically examine whether restrictive abortion laws have an effect on the incidence of unintended pregnancy. The empirical results showed that no Medicaid funding, mandatory counseling laws, two-visit laws and antiabortion attitudes had no significant effect on the unintended and unwanted pregnancy rate and ratio. Parental involvement laws, however, which only impact teen minors (less than 18 years of age), are found to have a significant negative effect on the various measures of the incidence of unintended pregnancy. This finding may seem self-contradictory or paradoxical since teen minor 
pregnancies are less than 6 percent of all pregnancies. This finding is consistent with the hypothesis that parental involvement laws cause changes in the pregnancy avoidance behavior of teen minors, by altering their frequency of unprotected sexual activity and/or contraceptive use, and this behavioral modification effect is perpetuated over adult women's childbearing span of 18-44 years of age.

\section{References}

[1] L. B. Finer and S. K. Henshaw, "Disparities in rates of unintended pregnancy in the United States, 1994 and 2001," Perspectives on Sexual and Reproductive Health, vol. 38, no. 2, pp. 90-96, 2006.

[2] A. Sonfield, K. Kost, R. B. Gold, and L. B. Finer, "The public costs of births resulting from unintended pregnancies: national and state-level estimates," Perspectives on Sexual and Reproductive Health, vol. 43, no. 2, pp. 94-102, 2011.

[3] P. B. Levine, Sex and Consequences: Abortion Policy and the Economics of Fertility, Princeton University Press, Princeton, NJ, USA, 2004.

[4] T. Joyce and R. Kaestner, "State reproductive policies and adolescent pregnancy resolution: the case of parental involvement laws," Journal of Health Economics, vol. 15, no. 5, pp. 579-607, 1996.

[5] M. H. Medoff, "Price, restrictions and abortion demand," Journal of Family and Economic Issues, vol. 28, no. 4, pp. 583599, 2007.

[6] M. H. Medoff, "The response of abortion demand to changes in abortion costs," Social Indicators Research, vol. 87, no. 2, pp. 329-346, 2008.

[7] M. H. Medoff, "State abortion policy and the long-term impact of parental involvement laws," Politics and Policy, vol. 38, no. 2, pp. 193-221, 2010.

[8] L. B. Finer and K. Kost, "Unintended pregnancy rates at the state level," Perspectives on Sexual and Reproductive Health, vol. 43, no. 2, pp. 78-87, 2011.

[9] J. Lewis and J. O. Shimabukuro, "Abortion law development: a brief overview," Almanac of Policy Issues, 2001.

[10] T. J. Kane and D. Staiger, "Teen motherhood and abortion access," Quarterly Journal of Economics, vol. 111, no. 2, pp. 467-506, 1996.

[11] M. H. Medoff, "Abortion costs, sexual behavior, and pregnancy rates," Social Science Journal, vol. 45, no. 1, pp. 156-172, 2008.

[12] M. H. Medoff, "Nonmarital births and state abortion policies," Social Work in Public Health, vol. 25, no. 5, pp. 454-469, 2010.

[13] M. H. Medoff, "Restrictive abortion laws, antiabortion attitudes and women's contraceptive use," Social Science Research, vol. 41, no. 1, pp. 160-169, 2012.

[14] K. Kelly and L. Grant, "State abortion and nonmarital birthrates in the post-welfare reform era: the impact of economic incentives on reproductive behaviors of teenage and adult women," Gender and Society, vol. 21, no. 6, pp. 878-904, 2007.

[15] P. England and B. S. Kilbourne, "Feminist critiques of the separative model of self: implications for rational choice theory," Rationality and Society, vol. 2, no. 2, pp. 156-171, 1990.

[16] P. B. Levine, "The sexual activity and birth control use of American teenagers," in Risky Behavior Among Youths: An Economic Analysis, J. Gruber, Ed., pp. 167-218, University of Chicago Press, Chicago, Ill, USA, 2001.
[17] S. L. Averett, D. I. Rees, and L. M. Argys, "The impact of government policies and neighborhood characteristics on teenage sexual activity and contraceptive use," American Journal of Public Health, vol. 92, no. 11, pp. 1773-1778, 2002.

[18] P. B. Levine, "Parental involvement laws and fertility behavior," Journal of Health Economics, vol. 22, no. 5, pp. 861-878, 2003.

[19] B. Sen, "Frequency of sexual activity among unmarried adolescent girls: do state policies pertaining to abortion access matter?" The Eastern Economic Journal, vol. 32, no. 2, pp. 313330, 2006.

[20] T. Joyce, R. Kaestner, and S. Colman, "Changes in abortions and births and the Texas parental notification law," The New England Journal of Medicine, vol. 354, no. 10, pp. 1031-1038, 2006.

[21] M. H. Medoff, "The impact of state abortion policies on teen pregnancy rates," Social Indicators Research, vol. 97, no. 2, pp. 177-189, 2010.

[22] J. Klick and T. Stratmann, "Abortion access and risky sex among teens: parental involvement laws and sexually transmitted diseases," Journal of Law, Economics, and Organization, vol. 24, no. 1, pp. 2-21, 2008.

[23] B. Sen, "A preliminary investigation of the effects of restrictions on Medicaid funding for abortions on female STD rates," Health Economics, vol. 12, no. 6, pp. 453-464, 2003.

[24] R. T. Michael, "Education and the derived demand for children," Journal of Political Economy, vol. 81, no. 2, part 2, pp. S128-S164, 1973.

[25] R. J. Willis, "A new approach to the economic theory of fertility behavior," Journal of Political Economy, vol. 81, no. 2, part 2, pp. S14-S64, 1973.

[26] Guttmacher Institute, State policies in brief, Guttmacher Institute, New York, NY, USA, 2008.

[27] NARAL Foundation, Who Decides? the Status of Women's Reproductive Rights in the United States, NARAL Foundation, Washington, DC, USA, 2006.

[28] R. M. Blank, C. C. George, and R. A. London, "State abortion rates: the impact of policies, providers, politics, demographics, and economic environment," Journal of Health Economics, vol. 15, no. 5, pp. 513-553, 1996.

[29] D. Haas-Wilson, "The impact of state abortion restrictions on minors' demand for abortions," Journal of Human Resources, vol. 31, no. 1, pp. 140-158, 1996.

[30] U.S. Bureau of the Census. U.S. Census of the Population, State reports, Government Printing Office, Washington, DC, USA, 2003.

[31] S. J. Schmidt, Econometrics, McGraw-Hill, New York, NY, USA, 2005.

[32] R. K. Jones and K. Kost, "Underreporting of induced and spontaneous abortion in the United States: an analysis of the 2002 National Survey of Family Growth," Studies in Family Planning, vol. 38, no. 3, pp. 187-197, 2007.

[33] K. Kost, L. B. Finer, and S. Singh, "Variation in state unintended pregnancy rates in the United States," Perspectives on Sexual and Reproductive Health, vol. 44, no. 1, pp. 57-64, 2012.

[34] T. Joyce and R. Kaestner, "The impact of mandatory waiting periods and parental consent laws on the timing of abortion and state of occurrence among adolescents in Mississippi and South Carolina," Journal of Policy Analysis and Management, vol. 20, no. 2, pp. 263-282, 2001.

[35] A. Tomal, "Parental involvement laws and minor and nonminor teen abortion and birth rates," Journal of Family and Economic Issues, vol. 20, no. 2, pp. 149-162, 1999.

[36] R. K. Jones, A. Purcell, S. Singh, and L. B. Finer, "Adolescents' reports of parental knowledge of adolescents' use of sexual 
health services and their reactions to mandated parental notification for prescription contraception," The Journal of the American Medical Association, vol. 293, no. 3, pp. 340-348, 2005.

[37] I. V. Sawhill, “Teenage sex, pregnancy, and nonmarital births," Gender Issues, vol. 23, no. 4, pp. 48-59, 2006. 


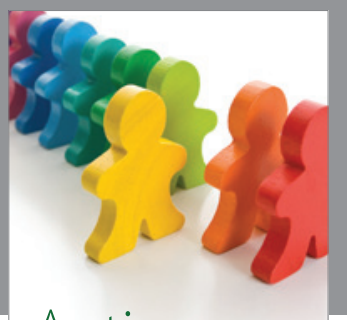

Autism

Research and Treatment
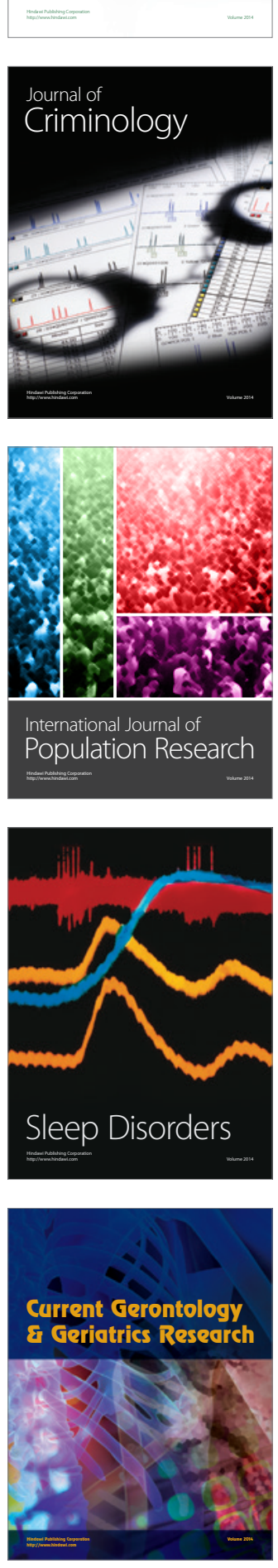
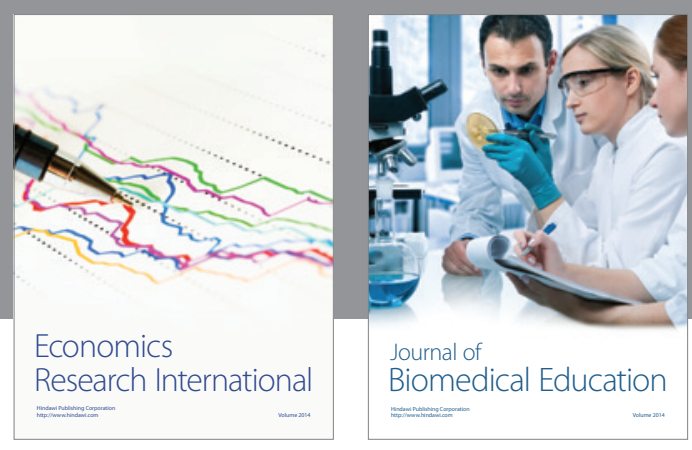

Journal of

Biomedical Education

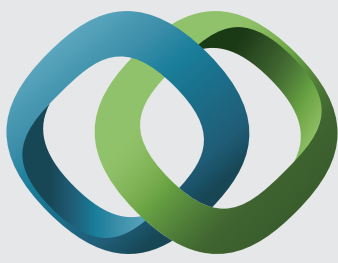

\section{Hindawi}

Submit your manuscripts at

http://www.hindawi.com
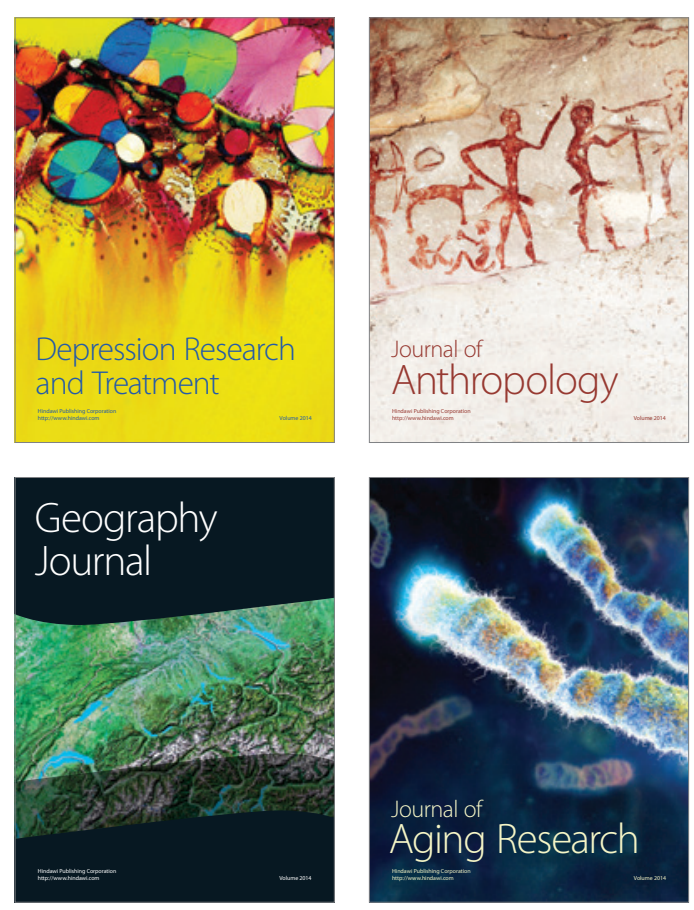

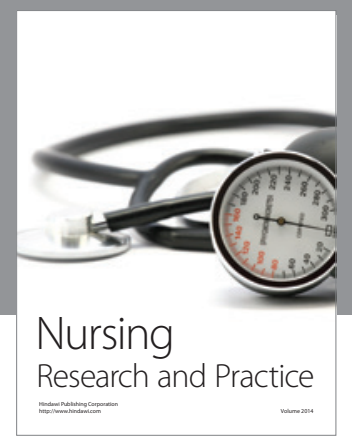

Nursing

Research and Practice

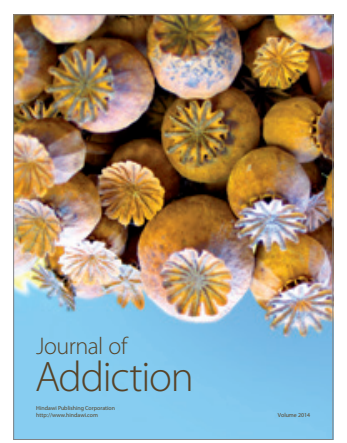

Child Development

Research

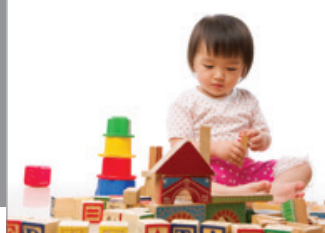

迥
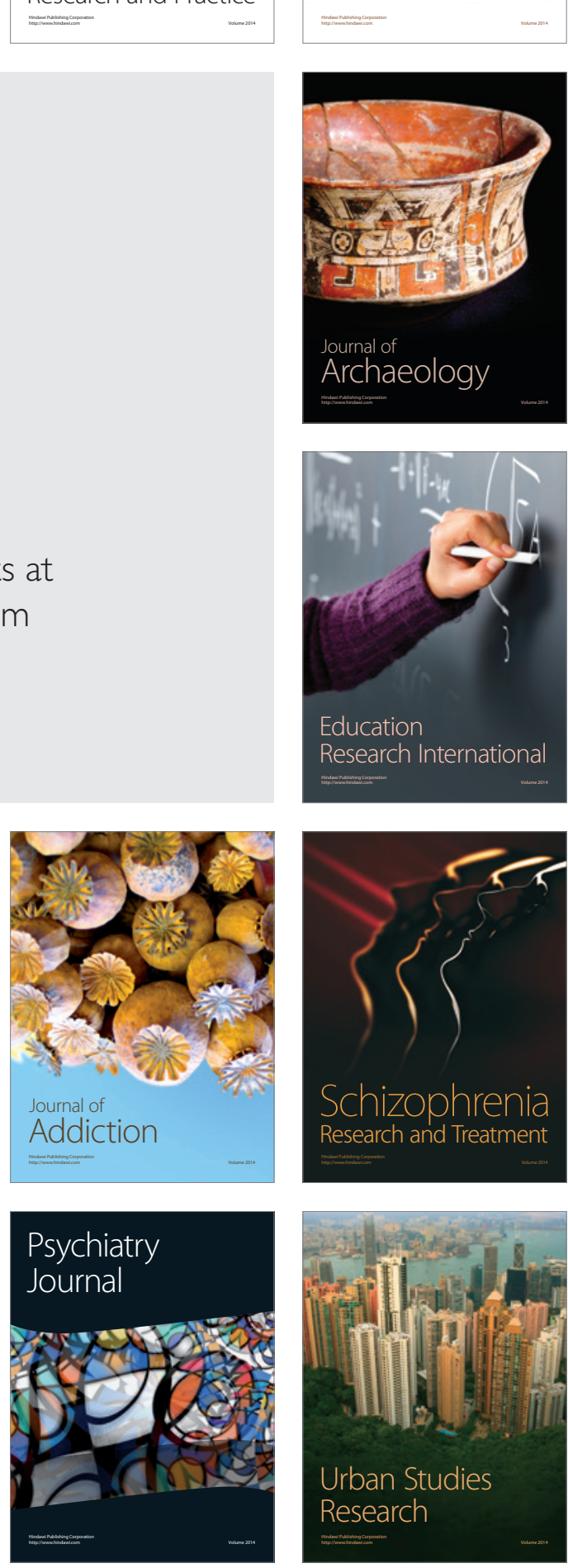